\title{
A NARRADORA ESTÁ ENTRE NÓS: O FIAR DA NARRATIVA NOS CONTOS- RELATOS DE INSUBMISSAS LÁGRIMAS DE MULHERES (2011)
}

\author{
Juliana Cristina Costa* \\ Marcos Vinícius Ferreira de Oliveira**
}

\begin{abstract}
RESUMO: A partir das considerações feitas por Walter Benjamin acerca do narrador moderno e no que constitui uma boa narrativa, este artigo busca analisar como a narradora de Insubmissas lágrimas de mulheres (2011), de Conceição Evaristo, é representada. Através de uma análise panorâmica dos contos que constituem a obra, é possível perceber que a construção narrativa se dá pelo entrecruzamento do real com o ficcional e a narradora se coloca como uma ouvinte de histórias que buscam evidenciar as experiências de mulheres a qual se identifica.
\end{abstract}

Palavras-chave: Walter Benjamin. Literatura negra brasileira. Narrativa.

\section{Introdução}

Em suas considerações acerca da obra de Nikolai Leskov, Walter Benjamin apresenta uma inquietante afirmação: "O narrador não está, de fato, presente entre nós em sua atualidade viva" (BENJAMIN, 2012, p. 198). O autor ao explicitar o declínio da arte de narrar como consequência da precariedade de se comunicar experiências, constata que os indivíduos modernos, embora em contato com muitas informações não conseguem intercambiar experiências, sendo que apesar do desenvolvimento tecnológico não houve o aprimoramento de trocas reais de experiência, mas a reconfiguração do modo de vida social, por exemplo, através da internet.

Nas referidas considerações, Benjamin ainda manifesta que embora se esteja em contato com uma gama de notícias, os sujeitos continuam "pobres em histórias surpreendentes", pois os fatos são apresentados com explicações, estando a "serviço da informação". Isto pode ser relacionado com a noção de "midiação da cultura moderna" de J. B. Thompson (1995) que se refere ao processo geral de transmissão das formas simbólicas que é mediado pelos aparatos técnicos e institucionais das indústrias da mídia. (THOMPSON, 1995, p. 12). O teórico inglês ainda apresenta que esta "midiação" ocorre a serviço de interesses institucionais, sendo assim não se pode desconsiderar a presença das relações de poder em seu controle.

Narrar é contar histórias. Ao possuir uma forte relação com a oralidade, a narrativa se faz como modo de registro e difusão de experiências. Benjamim também expressa a relevância do ouvinte, que na cultura moderna não "fia ou tece" a história enquanto a ouve.

\footnotetext{
* Mestre em Letras: Estudos Literários pela Universidade Federal de Juiz de Fora (UFJF) e graduada em Letras/Literaturas pela Universidade Federal de Viçosa (UFV).

E-mail: jucostaletras@gmail.com

** Professor Adjunto de Literatura Portuguesa na Faculdade de Letras da UFJF. Doutor em Letras: Estudos Literários pela UFJF. Mestre em Letras pela Universidade Federal do Espírito Santo (UFES). Especialista em Ciências Humanas pela UFJF.

E-mail: viniciusmestico@gmail.com
} 
Pode-se considerar este "fiar" ou "tecer" a história como sendo a reflexão do ouvinte sobre aquilo que ouve relacionando com as suas próprias experiências.

Em Insubmissas lágrimas de mulheres (2011) é possível percebe a ação de ouvinte de histórias, ou experiências, praticado pela narradora. A obra é composta por treze contos, os quais neste artigo serão referenciados como contos-relatos, pois o gênero literário "conto" se mistura com gênero textual "relato"; e cujos títulos são os nomes das personagens-relatantes, personagens que também ocupam em um dado momento da narrativa a função de narradoras. As categorias de composição literária (personagem, narrador, por exemplo) ficam difíceis de serem definidas e devido ao fato dos textos literários em questão poderem ser considerados relatos ficcionalizados, permitindo a relação com o conceito de "escrevivência" formulado pela escritora Conceição Evaristo, que é também crítica literária. Este conceito corresponde a noção de que o que é escrito também pode ter sido vivido, isto é, que a construção da narrativa não é feita a partir de um distanciamento da experiência do autor em relação a experiência narrada.

A relação mundo social e literatura é complexa. Através da historiografia literária pode-se observar que a literatura era um elemento "exclusivo" da cultura burguesa, sendo que as representações literárias, reconhecidas, estavam em consonância com esta cultura. A partir da década de 1970, mediante a intensificação das reivindicações dos movimentos sociais, dentre eles o movimento negro e feminista, é manifestado o questionamento dessas representações e a contestação do espaço literário marcado pelos valores hegemônicos.

A literatura afro-brasileira ou negra surge com objetivo de desconstruir as representações literárias feitas sobre o indivíduo negro. Transformando o discurso literário em instrumento de reconfiguração do imaginário social, denunciando principalmente o racismo tão internalizado nas relações sociais. O reconhecimento tardio dos precursores, como, por exemplo, Maria Firmina dos Reis e Luiz Gama, dessa literatura possibilita a reflexão sobre a literatura brasileira ser um espaço que sofre as influências das relações assimétricas de poder.

Em Gênero e etnia: escre(vivência) de dupla face (2009), Conceição Evaristo expressa que através da escrita a mulher negra em sua dupla condição, que a sociedade inferioriza, mulher e negra, busca afirmar ao mesmo tempo estas "duas faces da mesma moeda". Sendo assim, Evaristo expressa que a experiência do escritor, sujeito social, se faz presente de alguma forma em sua escrita. E também aponta para a impossibilidade de neutralidade discursiva na escrita literária.

Além disso, Benjamim ainda fala nas considerações sobre Leskov acerca da "atualidade viva" do narrador no que tange a troca de "experiências comunicáveis", sendo assim esta atualidade viva pode ser percebida na narradora de Insubmissas lágrimas de mulheres (2011), em que se faz ouvinte e divide a posição de narradora com as personagensrelatantes. Se o narrador moderno estava em via de extinção como apontou o teórico, o narrador pós-moderno configura-se de modo diverso, exercendo a funcionalidade de acordo com a intencionalidade da escritora ou escritor, aumentando ou diminuindo a distância estética com o público leitor como ocorre na obra em estudo. 


\title{
A narradora está entre nós: a narrativa em várias vozes
}

Na narrativa de Insubmissas lágrimas de mulheres (2011), a narradora pode ser vista como a representação literária da escritora. No início da obra, naquilo que pode ser considerado um prefácio, embora não seja nomeado como tal, são expressas as seguintes considerações pela escritora:

\begin{abstract}
Gosto de ouvir, mas não sei se sou a hábil conselheira. Ouço muito. Da voz outra, faço a minha, as histórias também. E no quase gozo da escuta, seco os olhos. Não os meus, mas de quem conta. $\mathrm{E}$, quando de mim uma lágrima se faz mais rápida que o gesto de minha mão a correr sobre o meu próprio rosto, deixo o choro viver. E depois, confesso a quem me conta, que emocionada estou por histórias que nunca ouvi e nunca imaginei para nenhuma personagem encarnar (EVARISTO, 2011).
\end{abstract}

Acima, a escritora se coloca como quem gosta de ouvir histórias mais do que opinar sobre elas. Neste ato de ouvir, manifestado em interação com quem lhe conta a história, e se colocando como uma narradora que se aproxima para poder narrar o que the foi narrado, visibilizando vozes e até mesmo absorvendo-as como quem as vive. Quando manifesta que se emociona com as histórias e que estas nunca por ela foram imaginadas para a criação de personagens, possibilita compreender que faz uma relação entre ficção e realidade, considerando a dificuldade de se escrever determinadas experiências.

Ainda a escritora expressa:

\begin{abstract}
Portanto, estas histórias não são totalmente minhas, mas quase que me pertencem, na medida em que, às vezes, se (con)fundem com as minhas. Invento? Sim, invento sem o menor pudor. Então, as histórias não são inventadas? Mesmo as reais, quando são contadas. Desafio alguém a relatar fielmente algo que aconteceu. Entre o acontecimento e a narração do fato, alguma coisa se perde e por isso se acrescenta. O real vivido fica comprometido. E quando se escreve, o comprometimento (ou não comprometimento) entre o vivido e escrito aprofunda mais o fosso. Entretanto, afirmo que, ao registrar estas histórias continuo no premeditado ato de traçar uma escrevivência (EVARISTO, 2011).
\end{abstract}

Ao dizer que as histórias que constituem o livro não são de sua autoria, mas se fundem e se confundem com as suas próprias histórias, pode-se considerar que o termo história também é empregado no sentido de "experiência vivida". Ainda neste excerto final do texto que inicia o livro, a autora manifesta uma reflexão acerca do real e da versão sobre o real, considerando que o que é narrado nunca corresponde com exatidão com o que foi vivido. Ao expressar sobre o comprometimento, coloca em questão o papel do escritor em relação a sua própria escrita, há o uso do verbo "comprometimento" com duplo sentido, isto também ocorre com o termo "história", demonstrando que a narração de um fato pode ser comprometida, no sentido de ser 'afetada' por quem narra, já que quem narra é um sujeito repleto de vivências que podem interferir no modo como interpreta os fatos.

Desse modo, a escritora se coloca como quem faz o registro de histórias alheias e também expressa que o objetivo deste ato é o de traçar uma escrevivência que pode ser compreendida como a possibilidade de escrever experiências que dialogam de alguma forma com as da própria autora. Ainda, quando fala que este ato é proposital, a escritora permite a reflexão sobre a escrita literária como sendo um ato de intencionalidade, isto é, que serve a

IPOTESI, JUIZ DE FORA, v. 23, n. 2, p. 119-125, jul./dez. 2019 
algum propósito ideológico ou social.

No conto-relato "Aramides Florença", como também nos demais textos presentes na obra, ocorre dois relatos, o do encontro da narradora com a personagem que se dá por meio de uma visita domiciliar e a da personagem- relatante acerca da própria história, sendo que em algumas situações a primazia do ato de narrar é dada a personagem. Observe o excerto a seguir: "Quando cheguei à casa de Aramides Florença, a minha igual, estava assentada em uma pequena cadeira de balanço e trazia, no colo, um bebê que tinha a aparência de quase um ano" (EVARISTO, 2011, p. 11).

Pode-se perceber que a narradora já no início da narrativa desempenha através da expressão "a minha igual" a ênfase da relação entre si e a personagem-relatante. Vale ressaltar que a escritora Conceição Evaristo é uma mulher negra e este lugar social é afirmado em seus textos críticos e também em palestras e entrevistas, sendo assim, mesmo que não marque textualmente o que tange esta semelhança com a personagem, pode-se inferir que seja a de gênero e o de raça, sendo Aramides Florença também uma mulher negra.

A narrativa se constitui com uma mistura de vozes, da narradora e da personagemrelatante. A voz de Aramides se manifesta no segundo parágrafo ao apresentar o filho Emildes Florença à autora que a visita e no final da narrativa quando é narrado o desencadeamento da história que envolve o relato de um fato doloroso de sua vida: quando foi violentada pelo esposo que não aceitava a atenção que a mulher fornecia ao filho desde a gravidez e após o nascimento do filho.

O livro não apresenta uma uniformidade no modo como são desencadeadas as narrativas. No conto-relato "Shirley Paixão", a narrativa é construída de modo diferente que em "Aramides Florença. Esta variedade de modos de narrar pode ser relacionada ao fato de serem diferentes as mulheres e histórias que são narradas. Neste conto-relato, a narrativa se inicia da seguinte maneira:

Foi assim - me contou Shirley Paixão. Quando vi caído o corpo ensanguentado daquele que tinha sido meu homem, nenhuma compaixão tive. E se não fosse uma vizinha, eu continuaria o meu insano ato. Queria matá-lo, queria acabar com aquele malacafento, mas ele é tão ruim que não morreu! Não adianta me perguntar se me arrependi. Arrependi não. Confessei a polícia o meu desejo, a minha intenção (EVARISTO, 2011, p. 25).

A narrativa desse conto é feita por Shirley Paixão, sendo a história de uma mulher que quase mata o marido depois de vê-lo tentar violentar uma de suas filhas, no decorrer do relato informa sobre a descoberta de que a situação flagrada não era a primeira vez e que o homem havia violentado sexualmente a filha por várias vezes. A narradora-autora não marca sua voz no texto, isto se dá, talvez, pelo conteúdo violento da narrativa o qual de todos os contosrelatos é o que mais pode provocar no leitor a indignação ou o mesmo ódio que Shirley Paixão expressa constantemente enquanto narra.

Pode-se considerar que a narradora-autora no ato de relatar decidiu reproduzir totalmente a voz da relatante e faz com que o leitor tenha a sensação de estar ouvindo a história diretamente da fonte. Aqui as vozes se fundem, mas do que se confundem. A construção da narrativa também pode ser compreendida como sendo uma narrativa pósmoderna, quando a autora subverte o paradigma narrativo em prol de evidenciar questões que

IPOTESI, JUIZ DE FORA, v. 23, n. 2, p. 119-125, jul./dez. 2019 
envolvem a realidade social. Em Poética do pós-modernismo (1991), Linda Hutcheon expressa que "as fronteiras mais radicais que já se ultrapassaram foram aquelas existentes entre a arte e a vida" (HUTCHEON, 1991, p. 27), sendo assim a narrativa instaura a dúvida sobre o que é real e o que é ficcional.

Embora na obra se narre "experiências vividas", que para Benjamin é o mesmo que "vivências", a escrita se dá através da transmissão destas vivências, as quais demonstram também que a identidade negra, principalmente da mulher negra, é perpassada por diversas subjetividades. Sabendo que as considerações do autor sobre a narrativa foram feitas referente a outro contexto social e período histórico, diferente do qual a escritora em questão estar inserida, ressalta-se que na narrativa de Insubmissas lágrimas de mulheres (2011) a narradora, ao contrário do que considerou o autor sobre o narrador moderno, "está entre nós", quando ao transparecer experiências, promove o evidenciamento de vozes e diminui a distância entre o que é narrado com a sua própria experiência.

Além disso, a narradora não aconselha e nem opina, apenas relata e expõe as vozes das personagens-relatantes, indo contra a concepção de Benjamin de que o narrador seria uma autoridade capaz de dar conselhos e orientações. O papel exercido pela narradora corresponde ao que Audrey Lorde considera ser "a transformação do silêncio em linguagem e ação" que consiste em um ato de autorrevelação. Ao trazer à tona as narrativas que não são suas e as transformando através da escrita literária, promove a difusão das experiências e com elas a denúncia de algumas situações sociais.

Segundo Linda Hutcheon (1991), a "auto-ficção" corresponde ao modo pós- moderno de escrever, como sendo também a "auto-língua" a linguagem de quem conta estórias. Estas características estão presentes na narrativa de Insubmissas lágrimas de mulheres (2011) quando a escritora si ficcionaliza em seu próprio texto e quando na linguagem narrativa deixa bem claro que está a contar um ocorrido, este é o que gera a história dentro da história, o relato do relato. Há também a noção de experiência ligada à transmissão de sabedoria, na qual Benjamin considera ser a funcionalidade de uma boa narrativa.

Se no período moderno, a categoria "narrador" era considerada como extinta por Benjamin, a partir do período designado pós-moderno se pode observar que está categoria se configura de diferentes modos. Adorno (2012) ao falar da posição do narrador no romance contemporâneo expressa em suas notas sobre literatura as seguintes considerações:

A distância é também encolhida pelos narradores menores, que já não ousam escrever nenhuma palavra que, enquanto relato factual, não peça desculpas por ter nascido. Se neles se anuncia a fraqueza de um estado de consciência que não tem fôlego o suficiente para tolerar a sua própria representação estética, e que quase não produz mais homens capazes dessa representação, então isso significa que, na produção mais avançada, que não permanece estranha a essa fraqueza, a abolição da distância é um mandamento da própria forma, um dos meios mais eficazes para atravessar o contexto do primeiro e expressar o que lhe é subjacente, a negatividade do positivo (ADORNO, 2012, p. 61-62).

A partir dessas colocações sobre a distância estética, pode-se considerar que Conceição Evaristo realiza o processo de encolhimento desta distância nos contos presentes

\footnotetext{
${ }^{1}$ Comunicação de Audrey Lorde no painel "Lésbicas e literatura” da Associação deLínguas Modernas.
}

IPOTESI, JUIZ DE FORA, v. 23, n. 2, p. 119-125, jul./dez. 2019 
em Insubmissas lágrimas de mulheres (2011) em prol de fornecer uma reflexão acerca do texto literário e a sua ligação com o real. E também como modo de colocar-se no mesmo plano de enunciação de suas personagens-relatantes, estabelecendo, propositalmente, uma dificuldade de delineamento do que seja relato e do que seja ficção, podendo promover o cancelamento da diferença entre os dois gêneros textuais.

Segundo Adorno, "contar algo significa ter algo especial a dizer, e justamente isso é impedido pelo mundo administrado pela estandardização e pela mesmice (ADORNO, 2012, p. 56). Neste viés, pode-se pensar: o que tem de especial a ser enunciado pela narrativa da referida obra? Além da presença constante nos contos-relatos dos efeitos do patriarcado na vida de diferentes mulheres negras, há também, em alguns casos, a junção do mesmo com o racismo, como ocorre no conto "Maria do Rosário Imaculada dos Santos" em que a protagonista é sequestrada na infância e colocada em condição semelhante a da escravidão. No conto "Isaltina Campo Belo", estes fatores somam-se com a homofobia em que a personagem sofre um estupro coercitivo por não se reconhecer na identidade de gênero a qual a sociedade lhe percebe.

A posição privilegiada do narrador é transformada por Conceição Evaristo quando a compartilha com as personagens ou relatantes. Ao narrar distintas "experiências vividas" de mulheres negras, manifesta a capacidade de superação das mesmas. É possível considerar que a intencionalidade literária consista em visibilizar a multiplicidade de subjetividades que a identidade feminina negra se compõe, indo contra o processo de reificação da experiência dos sujeitos negros, principalmente, das mulheres negras.

\section{Conclusão}

A narradora em Insubmissas lágrimas de mulheres (2011), ao contar o que lhe foi contado, ilustra a origem na oralidade da arte de narrar. Respeitando a tradição narrativa, mas ao mesmo tempo a questiona ao anular a distância estética entre narrador e personagem. A construção narrativa provoca a reflexão de que toda narrativa constitui uma versão de algum fato, o que é manifestado pela autora no texto que corresponde ao prefácio da obra.

Além disso, tal obra manifesta um teor sociopolítico ao evidenciar distintas vivências de mulheres negras na sociedade, rompendo com a reificação de experiências, fornecendo ao leitor o contato com as vivências sociais, políticas e afetivas das personagens-relatantes. Ainda, pode ser percebido que independente de quem enuncia ou narrar, certas experiências adquirem força quando são feitas em primeira pessoa, sendo assim, percebe que no que tange o desencadeamento dos fatos narrados, quando são de extrema violência ou angústia, a voz narrativa fica sob o controle da "personagem".

O leitor se percebe também como ouvinte e através do jogo de voz narrativa tem a possibilidade de esquecer a presença da narradora-autora e ter a sensação de ouvir direto da fonte o relato. O título da obra remete a insubmissão, através da metáfora e da metonímia, pois o termo "lágrimas" pode remeter à corporeidade e à subjetividade de mulheres, além de promover a compreensão de que as experiências narradas, embora de sofrimento, também são de superação.

IPOTESI, JUIZ DE FORA, v. 23, n. 2, p. 119-125, jul./dez. 2019 


\section{LA NARRADORA ESTÁ ENTRE NOSOTROS: EL GIRO DE LA NARRATIVA EM LOS CUENTOS-RELATOS DE INSUBMISSAS LÁGRIMAS DE MULHERES (2011)}

RESUMEN: A partir de las consideraciones hechas por Walter Benjamin acerca del narrador moderno y en lo que constituye una buena narrativa, este artículo busca analizar como la narradora en la obra Insubmissas lágrimas de Mujeres (2011) de Conceição Evaristo es representada. A través de un análisis panorámico de los cuentos que constituyen la obra, es posible percibir que la construcción narrativa se da por el entrecruzamiento de lo real con lo ficcional y la narradora se coloca como una oyente de historias que buscan evidenciar las experiencias de mujeres a las que se identifica.

Palabras-claves: Walter Benjamin. Literatura negra brasileña. Narrativa.

\section{Referências}

ADORNO, Theodor W. Notas de literatura. Tradução Jorge de Almeida. São Paulo: 34, 2012.

AUDRE, Lorde. Transformação do silêncio em linguagem em ação. Disponível em http://www.geledes.org.br/a-transformacao-do-silencio-em-linguagem-e- acao/\#gs.8EBVThc. Acesso em: 03 fev. 2017.

BENJAMIN, Walter. Magia e técnica, arte e política. São Paulo: Brasiliense, 2012.

EVARISTO, Conceição. Insubmissas lágrimas de mulheres. Belo Horizonte: Nandyala, 2011. Gênero e etnia: uma escre(vivência) de dupla face - mesa de escritoras convidadas do X Seminário Nacional Mulher e Literatura, I Seminário Internacional Mulher e Literatura/UFB, 2003.

HUTCHEON, Linda. Poética do pós-modernismo. Tradução Ricardo Cruz. Rio de Janeiro: Imago, 1991.

THOMPSON. John B. Ideologia e cultura moderna: teoria social crítica na era dos meios de comunicação. Petrópolis: Vozes, 1995.

Data de submissão: 30/06/2019.

Data de aceite: 29/08/2019. 